\title{
STUDI ANALISIS PEMBINAAN PRESTASI EKSTRAKULIKULER FUTSAL DI SMAN 10 KOTA BENGKULU
}

\author{
Riyandi Sudrajat ${ }^{1}$, Yarmani $^{2}$, Santun Sihombing ${ }^{3}$ \\ ${ }^{123}$ Prodi Penjas, FKIP, Universitas Bengkulu, Kota Bengkulu , Indonesia
}

\begin{tabular}{l} 
Info Artikel \\
\hline Sejarah Artikel: \\
Diterima April 2020 \\
Direvisi April 2020 \\
Diterima April 2020 \\
Tersedia online April 2020 \\
-_ Kata kunci: \\
Pembinaan, Prestasi, Futsal
\end{tabular}

\section{Abstrak}

Penelitian ini bertujuan untuk mengetahui pembinaan prestasi ekstrakulikuler futsal di SMAN 10 Kota Bengkulu.Permasalahan yang dikaji dalam penelitian ini adalah bagaimanakah Pembinaan Prestasi Peserta Ekstrakulikuler Futsal di SMAN 10 Kota Bengkulu. Sumber data penelitian ini meliputi pembina, pelatih, dan peserta ekstrakulikuler, serta dokumen-dokumen.Dalam penelitian ini menggunakan metode kualitatif deskriptif. Teknik pengumpulan data menggunakan teknik observasi, kusioner, wawancara, dan dokumentasi. Sampel yang diteliti peserta futsal di SMAN 10 Kota Bengkulu yang berjumlah 28 siswa. Dari data yang diperoleh maka dapat disimpulkan bahwa, 1) Pembuatan program latihan dan perekrutan peserta ekstrakulikuler belum berjalan dengan baik, ditambah lagi tidak didukung dengan sarana dan prasarana yang memadai. 2) Tidak ada penyeleksian secara khusus untuk mengikuti kegiatan ekstrakulikuler Futsal di SMAN 10 Kota Bengkulu. 3). Pengarahan Ekstrakulikuler futsal di SMAN 10 Kota Bengkulu dalam hal waktu dan kedisiplinan sudah berjalan dengan baik. 4). Sumber pendanaan kegiatan ekstrakulikuler futsal di SMAN 10 Kota Bengkulu tidak memiliki dan khusus dari sekolah.

\section{Abstract}

This study aims to find out about futsal extracurricular achievements at SMAN 10 Kota Bengkulu. The problem examined in this study is how the Development of Futsal Extracurricular Participant Development at SMAN 10 Kota Bengkulu. The data sources of this study include coaches, trainers, and extracurricular participants, as well as documents. In this study using qualitative descriptive methods. Data collection techniques use observation, questionnaire, interview, and documentation techniques. The sample was studied by futsal participants at SMAN 10 Kota Bengkulu, totaling 28 students. From the data obtained, it can be concluded that, 1) The making of training programs and recruitment of extracurricular participants has not been going well, plus it is not supported by adequate facilities and infrastructure. 2) There is no 


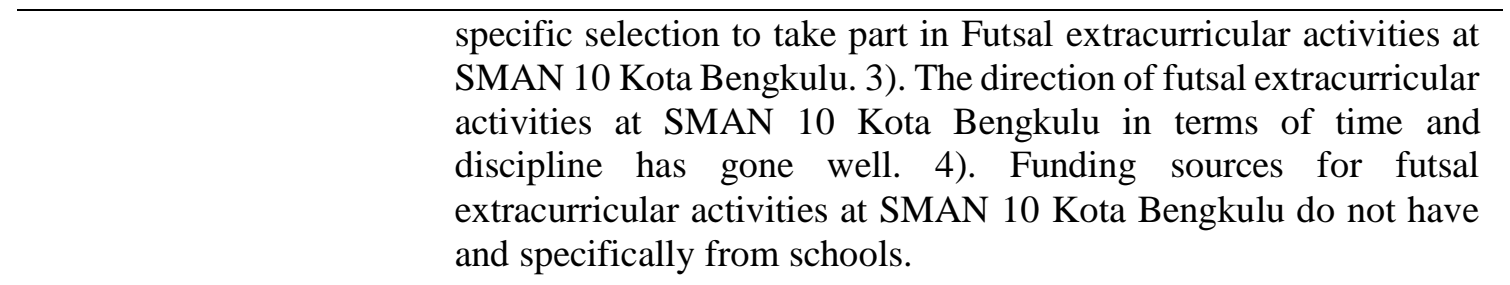

Alamat yang sesuai: Jl. Raden Fatah, Kota Bengkulu

ISSN (online)

Email_:riyandi16@gmail.com

ISSN (cetak)

\section{PENDAHULUAN}

Pendidikan merupakan faktor yang sangat penting dalam kehidupan manusia karena dengan adanya pendidikan diharapkan manusia dapat mengembangkan pengetahuan, keterampilan dan kreativitasnya. Keberhasilan dalam bidang pendidikan sangat ditentukan oleh keberhasilan dalam proses pembelajaran.

Di Indonesia kegiatan ekstrakulikuler bukanlah hal yang baru. Mulai dari sekolah dasar hingga perguruan tinggi. Kegiatan Ekstrakulikuler adalah Kegiatan tambahan yang dilakukan di luar jam pelajaran dapat di lakukan di sekolah ataupun di luar sekolah yang bertujuan untuk mendapatkan tambahan pengetahuan, keterampilan, atau wawasan serta membantu membentuk karakter peserta didik sesuai dengan minat dan bakat masing-masing.

Salah satu tujuan Pendidikan Jasmani Olahraga dan Kesehatan adalah meningkatnya gerak dasar siswa dalam keterampilan bermain. Maka ekstrakurikuler olahraga merupakan salah satu wahana untuk dapat mencapai tujuan Pendidikan Jasmani tersebut.

Salah satu cabang olahraga yang biasa dilaksanakan dalam kegiatan ekstrakurikuler adalah cabang olahraga futsal, Ekstrakurikuler futsal merupakan ekstrakurikuler yang favorit dan banyak diminati oleh siswa.

Fokus utama program latihan yang dirancang pelatih futsal SMA Negeri 10 KOTA BENGKULU terletak pada keterampilan dasar dan kekuatan , karena kekuatan dan keterampilan dasar ini sangat menunjang permainan yang baik.

Di dalam prestasinya tim ekstrakulikuler futsal SMAN 10 BENGKULU dapat di kategorikan belum terlalu menonjol di banding SMAN lain. Menurut data yang di dapat dari sekolah, di tahun 2013-2014 futsal SMAN 10 sering mendapatkan juara seperti piala FKPPI, Piala liga dewa, piala BJF, dan piala lainnya. Ketika tahun 2018 mulai terjadi penurunan, tim futsal SMAN 10 hanya mendapatkan 1 piala di GOR Bengkulu, dan hingga saat ini Futsal SMAN 10 sangat menurun dengan ditandai tidak adanya prestasi yang dapat di raih.

Pembinaan prestasi yang dilakukan sekolah juga belum mendukung sepenuhnya seperti dalam hal, sarana dan prasarana, program latihan, dan pengorganisasian. Maka dari itu, berdasarkan pengamatan yang dilakukan terhadap tim tersebut, ditemukan beberapa kekurangan yang belum disadari oleh tim pelatih.

Selain itu, pelatih juga akan mengadakan suatu tes atau evaluasi 
tingkat keberhasilan program latihan yang telah diberikan dalam meningkatkan keterampilan bermain anggota tim. Sehingga, akan diketahui seberapa tinggi perkembangan yang dialami oleh siswa dari program latihan tersebut. Berdasarkan uraian tersebut maka peneliti tertarik untuk melakukan penelitian yang berjudul " Studi Analisis Pembinaan Prestasi Ekstrakulikuler Futsal Di Sman 10 Kota Bengkulu”.

\section{Jenis Penilitian}

Menurut Endang Widi Winardi (2011: 4) Penelitian adalah suatu upaya sistematis dalam menemukan, menganalisis dan menafsirkan bukti-bukti empiris untuk memahami gejala atau menemukan jawaban terhadap suatu permasalahan yang terkaitdengan gejala itu. Penggunaan metode penelitian dalam sebuah penelitian harus tepat dan mengarah pada tujuan penelitian agar memperoleh hasil yang sesuai dengan tujuan yang diharapkan dan dapat di pertanggung jawabkan secara ilmiah.

\section{METODE}

Metode penelitian ini adalah penelitian deskriptif kualitatif, menurut Iskandar dalam Heru (2018 : 23) Penelitian deskriptif merupakan jenis tentang nilai variabel mandiri, baik satu variabel atau lebih (independent) berdasarkan indicator-indikator dari variabel yang diteliti tanpa membuat perbandingan atau menghubungkan antara variabel yang diteliti guna untuk eksplorasi dan klasifikasi dengan mendeskrifsikan sejumlah variabel yang berkenaan dengan masalah variabel yang diteliti. Sumber data yang diperoleh dari pelatih, pembina dan Peserta Ektrakulikuler Futsal SMAN 10 kota Bengkulu yang terkait dalam penelitian ini. Metode yang digunakan adalah survey digunakan untuk mendapatkan data dalam pengumpul data dari tempat tertentu yang alamiah (bukan buatan), tetapi peneliti melakukan perlakuan dalam pengumpulan data, Sugiyono (2012:6).

\section{HASIL}

\section{Perencanaan}

Perencanaan yang dilakukan ektrakurikuler futsal SMA Negeri 10 Kota Bengkulu untuk meningkatkan prestasi ektrakurikuler futsal dengan memberikan program latihan yang lebih baik dalam hal teknik, fisik, dan mental. Penentuan pelatih yang dilakukan pembina ekstrakurikuler futsal SMAN 10 tidak menggunakan seleksi secara khusus,

Pembina memberikan kewenangan kepada guru olahraga sebagai pelatih ekstrakurikuler futsal, dan di bantu dengan salah satu alumni, dengan standar kreteria pelatih, pihak sekolah tidak memilih pelatih yang berlisensi dari luar sekolah di karenakan keterbatanya biaya untuk menyewa pelatih dari luar. Perekrutan peserta ekstrakurikuler futsal di SMAN 10 Kota Bengkulu juga tidak menggunakan seleksi secara khusus. Bagi peserta akan di data oleh pelatih dan bisa langsung bergabung di ekstrakurikuler futsal. Sarana dan prasarana ekstrakurikuler futsal di SMAN 10 Kota Bengkulu masih sangat kurang memadai seperti, bola, kuun, rompi dan kostum untuk bertanding. Maka pihak sekolah akan berusaha memenuhi fasilitas yang masih sangat kurang, karena sarana dan prasarana adalah suatu faktor pendukung pembinaan prstasi. Pihak sekolah juga akan berusaha memberi apresiasi untuk siswa berprestasi yang telah membawa nama baik sekolah. Untuk kegiatan ekstrakulikuler futsal di SMAN 10 Kota Bengkulu dipercayakan oleh pembina dan pelatih. 


\section{Pengorganisasian}

Data siswa yang dimiliki ektrakulikuler futsal SMA Negeri 10 Kota Bengkulu dari tahun ke tahunya meningkat, sekarang berjumlah 28 siswa yang aktif mengikuti ektrakurikuler futsal SMA Negeri 10 Kota Bengkulu. Data prestasi yang dimiliki ektrakurikuler futsal SMA Negeri 10 Kota Bengkulu sudah cukup baik di tahun 2014 sampai 2017 di buktikan dengan di raihnya beberapa juara, namun terjadi penurunan pada tahun 2018 hingga sekarang. Selanjutnya data pelatih yang di miliki ektrakurikuler futsal SMA Negeri 10 Kota Bengkulu hanya memiliki satu pelatih yaitu guru olahraga yang mengajar di sekolah. Dan di tahun 2019 ini terjadi penambahan asisten pelatih yaitu salah satu alumni di SMAN 10 Kota Bengkulu.

Berikutnya dari keuangan yang di miliki SMA Negeri 10 Kota Bengkulu dana yang dimiliki berdasarkan uang komite siswa SMA Negeri 10 Kota Bengkulu dari hal tersebut setiap turnamen yang di ikuti sekolah memberikan uang pendaftaran dan air minum kepada pelatih.

\section{Pengarahan}

Berdasarkan hasil penelitian yang diperoleh mengenai waktu latihan dan tingkat kedisiplin peserta ektrakurikuler futsal SMA Negeri 10 Kota Bengkulu. Waktu kegiatan ekstrakurikuler futsal yang di tentukan dan dilakukan pelatih dengan jadwal latihan 3 hari dalam 1 minggunya, yaitu pada hari rabu, jumat, dan hari minggu. Kegiatan ekstrakurikuler futsal di mulai jam 16.00 WIB sampai dengan 17.45 WIB. Latihan pada hari rabu dan jum'at dilakukan di lapangan futsal SMA Negeri 10 Kota Bengkulu. Terkhusus hari minggu di lakukan di lapangan futsal puncak sukarami. Kedisiplinan peserta ekstrakurikuler futsal di SMAN 10 sudah cukup baik dibuktikan dengan kebanyakan dari peserta jarang terlambat sebelum di mulainya latihan, hanya ada beberapa anak yang datang terlambat dan sering tidak hadir pada waktu latihan. Pelatih memberlakukan hukuman bagi siswa yang terlambat datang, mereka akan di suruh lari dua keliling lapangan. Hal ini bertujuan untuk melatih kedisiplinan peserta.

\section{SIMPULAN}

\section{Simpulan}

Bardasarkan hasil penelitian dan pembahasan yang di peroleh, maka dapat ditarik kesimpulan, dalam perencanaan program latihan yang diberikan pelatih kepada peserta ekstrakurikuler futsal SMAN 10 Kota Bengkulu belum berjalan dengan baik karena pelatih hanya memberikan materi secara umum kepada peserta tanpa adanya pemberian materi fisik. Dalam penentuan pelatih ekstarulikuler futsal SMAN 10 Kota Bengkulu tidak menggunakan seleksi khusus, pihak sekolah belum bisa mengambil pelatih dari luar yang berlisensi karna keterbasan biaya sehingga, kewenangan seluruhnya di berikan kepada guru olahraga.begitupun dengan perekrutan peserta ekstrakulikuler futsal tidak menggunakan seleksi khusus karena kegiatan ini terbuka untuk seluruh siswa SMAN 10 yang berminat bergabung. Sarana dan prasarana dalam ekstrakulikuler futsal SMAN 10 Kota Bengkulu masih sangat kurang memadai karena belum memenuhi kebutuhan kegiatan ekstrakulikuler futsal SMAN 10 Kota Bengkulu.

Dalam pengorganisasian ekstrakurikuler futsal di SMAN 10 Kota Bengkulu, Data siswa yang dimiliki sekarang berjumlah 28 siswa yang masih aktif mengikuti. Data prestasi 
ekstrakurikuler futsal di SMAN 10 Kota Bengkulu sudah cukup baik di tahun 2014 sampai 2017 di buktikan dengan di raihnya beberapa kejuaraan, namun terjadi penurunan di tahun 2018 hingga sekarang tidak ada kejuaraan yang di raih. Kegiatan ekstrakurikuler futsal di SMAN 10 memiliki satu pelatih yaitu guru olahraga yang mengajar di SMAN 10 dan terjadi penambahan asisten pelatih yaitu salah satu alumni di sekolah SMAN 10.

Dalam pengarahan, waktu kegiatan ekstrakurikuler futsal di SMAN 10 Kota Bengkulu dilaksanakan 3 hari dalam seminggu, yaitu pada hari rabu, jumat, dan minggu. Kegiatan ini di laksanakan di lapangan futsal SMAN 10, sedangkan hari minggu latihan di lakukan di lapangan puncak Sukarami. Kegiatan ini di lakukan dimulai jam 16.00 WIB sampai dengan jam 17.45 WIB, kedisiplinan peserta sudah cukup baik karena kebanyakan peserta jarang terlambat sebelum dimulainya latihan.

\section{Saran}

Berdasarkan simpulan di atas maka peneliti menyarankan beberapa hal sebagai berikut:

1. Kepada pembina ekstrakurikuler futsal SMA Negeri 10 Kota Bengkulu agar bisa berkoordinasi dengan pihak sekolah untuk meningkatkan sarana dan prasarana yang lebih baik lagi untuk kedepannya, dan lebih berkoordinasi dengan pihak sekolah.

2. Kepada pelatih ekstrakurikuler futsal SMA Negeri 10 Kota Bengkulu agar bisa selalu berkoordinasi dengan pembina untuk terus memantau peserta, dan memberikan program latihan dengan baik sehingga dapat mempertahankan dan meningkatkan prestasi ektrakurikuler futsal SMAN 10 kota Bengkulu.

3. Kepada siswa ekstrakurikuler futsal SMA Negeri 10 Kota Bengkulu agar dapat mengikuti latihan dengan baik sehingga dapat meningkatkan kemampuan dan pencapaian prestasi untuk sekolah.

\section{DAFTAR PUSTAKA}

Almahdi, Z. 2008. Bisnis Futsal. Yogyakarta: Ayyana.

Asmar Jaya. 2008. Futsal : Gaya Hidup, Peraturan, dan Tips-tips Permainan. Yogyakarta: PustakaTimur

Aulia, R, N. 2007. Futsal. Bandung: PT Indah Jaya Adipratama

Charlim, dkk. 2011. MengenalLebihJauhTentang

Futsal. Jakarta: Multi KreasiSatudelapan.

Diana. 2008. Futsal. Yogyakarta: Empat Pilar Pendidikan.

Djoko, P, I. 2002. Dasar Kepelatihan. Yogyakarta: Andi.

H.Pardosi. 2008.Inspirasidan Spirit Futsal. Jakarta: RaihAsaSukses.

Hadi, R. 2007. Ilmu Kepelatihan Dasar. Semarang PKLO FIK UNNES : Cipta Prima Nusantara.

Harsono, 2015.

IlmuKepelatihanOlahraga.

Bandung: PT RemajaRosdakarya

Harsuki. 2012

PengantarManajemenOlahraga. Jakarta: PT Raja GrafindoPersada. 
Harzuki. 2003. Perkembangan Olahraga Terkini. Jakarata : PT Rajagrafindo Persada.

Irianto. 2002. Dasar Kepelatihan Olahraga. Yogyakarta: Rineka Cipta.

Jaya, A. 2008.Futsal, Gaya Hidup, Peraturan, dan Tips-tips Permainan. Yogyakarta: Pustaka Timur.

Kompri. 2016. Manajemen pendidikan. Yogyakarta: AR-RUZZ MEDIA.

Koni. 1998. Proyek Garuda Emas. Jakarta.

Kusnanik, N, W. 2013. "Evaluasi Manajemen Pembinaan Prestasi PRIMA Pratama Cabang Olahraga Panahan di Surabaya".Jurnal IPTEK Olahraga. Vol. 15 (2): hal. 125-137.

Lhaksana, Justinus. 2011. Taktik\&Strategi Futsal Modern. Jakarta: KawanPustaka.

Mansoer, H. 1989. Pengantar Manajemen. Jakarta : Depdikbud.

Mulyono, Muhammad Asriady. 2014. BukuPintarPanduan Futsal. Jakarta: NiagaSwadaya.

Narti, R. Aulia. 2007. Futsal. Bandung: PT Indah Jaya Adipratama.

Putra, A., Yarmani, Y., \& Arwin, A. IMPLEMENTASI PUSAT PENDIDIKAN DAN LATIHAN OLAHRAGA PELAJAR (PPLP) DALAM MENUNJANG PRESTASI OLAHRAGA $B E N G K U L U$ (Doctoral dissertation, Universitas Bengkulu).
Rahmadianti, T., \& Sugihartono, T. (2019). ANALISIS PERKEMBANGAN EKSTRAKURIKULER FUTSAL DITINGKAT SMP NEGERI KOTA BENGKULU. Kinestetik: Jurnal Ilmiah Pendidikan Jasmani, 3(2), 223-229.

Saputra, R. N., \& Yarmani, Y. (2019). PENGARUH METODE LATIHAN TERPUSAT DAN METODE LATIHAN ACAK TERHADAP KEMAMPUAN TEKNIK DASAR FUTSAL. Kinestetik: Jurnal Ilmiah Pendidikan Jasmani, 3(1), 108-117. .

Salim, S. 2009. 1 Hari Pintar Main Futsal. Jakarta: Buku Kita.

Setyobroto, S. 1992. Psikologi Kepelatihan. Jakarta : CV. Jaya Sakti.

Sopiatin, P. 2010 .Manajemen belajar berbasis kepuasan siswa. Bogor: Ghaliaindonesia

Sudarwati, L. 2007. Mental Juara Modal AtletBerprestasi. Jakarta: PT Raja GrafindoPersada.

Sutrisno.2007.

MempersiapkanPemainSepak Bola Berprestasi (1). Jakarta Barat: PT Musi Perkasa Utama.

Tohar. 2002. Ilmu Kepelatihan Lanjut. PLKO FIK UNNES. 